\title{
A Pilot study on a Cross Sectional Investigation of Science and Engineering Undergraduates: Motivation towards Learning English in Pakistan
}

\author{
*Insaf Ali Siming, Elizabeth M. Anthony, Muhammad Mujtaba Asad, Ajab Ali Lashari \\ Universiti Tun Hussein Onn Malaysia, Malaysia \\ Shah Abdul Latif University Khairpur Mirs' Pakistan \\ *justiceali_1@yahoo.com
}

\begin{abstract}
This research paper aims at to describe the results of pilot study on "A cross sectional investigation of Science and Engineering undergraduates' motivation towards learning English in Pakistan". The results of this research probably are useful and beneficial in the sense to test the instrument proposed for current study in particular and to provide recommendations for full study in general. Moreover Mix method design both qualitative and quantitative has been proposed for full study. But in piloting study the researchers only administered survey questionnaire in order to test the instrument. The researchers consulted the various studies on learners' motivational studies and used a modified questionnaire based on the Attitude Motivation Test Battery (AMTB) by Robert Gardner and the three stage model of Dorneyi. For the sampling researchers' selected convenience random sampling taking the names form hat policy was adopted. Questionnaire was divided in three parts, Part one of the questionnaire contained informants' demographic information. Second part of questionnaire contained ninety six closed ended items, and third part of the questionnaire contain three open ended questions. The population of this pilot study was Science and engineering students from Quaid-e-Awam University of Engineering and Technology. For reliability and validity check, all the data was interred in SPSS version 20 and cronbach's Alpha reliability of questionnaire remained 0.920 . This study intended to achieve the following aims and objectives (1) identify the motivational level of Science and Engineering undergraduates' towards learning English language (2) Establish the factors that effects undergraduates' motivation towards second language (L2) (3) Compare the motivational level between Science and Engineering undergraduates' towards learning English language. In later section of paper, a complete visual illustration of demographic information of initial findings based on gender, mother tongue, origin, departments and institutional status is graphically presented. Finally, it is highly recommended from the results obtained from the pilot study that instrument used in this study is valid and reliable and can be confidently used for full study. Due to its excellent level of validity, reliability and suitability
\end{abstract}

Keywords: Motivation, English language, Pilot study, Reliability, Validity

\section{Introduction}

The role of motivation has been emphasized in learning and teaching of any subject at all level. Yet it rather becomes crucial and significant when it comes the learning and teaching of English as foreign language because it is directly related to the social nature of learner and individual effort (Kobayashi and Viswat, 2007).According to the research study conducted by Oxford and Shaerin (1994), it is identified that success and failure of an individual depends upon the degree of motivation one possesses. Dornyei (2000b) argues that, "Motivation is responsible for why people decide to do something, how long they are willing to sustain the activity, and how hard they are going to pursue it "Therefore Motivation is considered as key factor for learning anything for every individual worldwide; the case of Pakistan is not different than that Where English is taught as compulsory subject at all undergraduate levels. The English language enjoys privileged status and is held at high position due to its potential importance in every perspective of life. So the purpose of present study is to highlight results of pilot study on "A cross sectional investigation of Science and Engineering undergraduates' motivation towards learning English in Pakistan". The results of this research probably are useful and beneficial in the sense to test the instrument proposed for current study in particular and to provide recommendations for full study in general. The present study intended to achieve the following aims and objectives (1) identify the motivational level of Science and Engineering undergraduates' towards learning English language (2) Establish the factors that effects undergraduates' motivation towards second language (L2) (3) Compare the motivational level between Science and Engineering undergraduates' towards learning English language. 


\section{Methodology}

In general, mix method design both qualitative and quantitative has been proposed for full study. (Reams and Tawale, 2008) suggested that mix method design is "necessary to uncover information and perspective to create corroboration and revels less biased and more accurate results". Moreover, the pilot study is "small scale test of the methods and procedures to be used at large scale" (Porta, 2008). But in piloting study the researcher only administered survey questionnaire in order to test the instrument. The researcher consulted the various studies on learners' motivational studies and used a modified questionnaire based on the Attitude Motivation Test Battery (AMTB) by Gardner (1985), and the three stage model of Dorneyi (1994).The AMTB is an established source which is used in present study to gauge the motivational level of Science and Engineering undergraduates' towards learning English in Pakistan. For the sampling purpose researchers' selected convenience random sampling taking the names form hat policy was adopted.

Format of Research Instrument: As a whole the questionnaire for current study was divided in three parts. Part one of the questionnaire contained informants' demographic information like gender, mother tongue, origin, department and institutional status. Second part of questionnaire contained (ninety six) 96 closed ended items, composed of five points Likert scale ranging from $(1=$ strongly disagree to 5 =strongly agree). The AMTB which is made of 12 scales/ factors and number of items on each scale in detail are indicated in table I from A to L to illicit participants' preferred motivational orientation:

Table 1: Representation of Number of factors and number of items on each scale
(A) Instrumental Orientation
( Number of items 1 to 4)
(C) English Teacher Evaluation
(Number of items 8 to 17)
(E) English Language Use Anxiety
(Number of items 27 to 36)
(G) Attitude towards Learning English
(Number of items 45 to 52)
(I) Desire to Learn English
(Number of items 61 to 67)
(K) Interest in Foreign Languages
(Number of items 78 to 87)
(B) Integrative Orientation
( Number of items 5 to 7)
(D) English Course Evaluation
(Number of items 18 to 26)
(F) Parental Encouragement
(Number of items 37 to 44)
(H) Attitude towards English Speaking People
(Number of items 53 to 60)
(J) Motivational Intensity
(Number of items 68 to 77)
(L) English Class Anxiety
(Number of items 88 to 96)

The third part of questionnaire contained contextual information. Three open ended questions were asked to collect qualitative data from informants. The respondents were informed that information collected through questionnaire will be kept confidential and will be used only for research purposes. So all the participants were appraised by sense of privacy and confidentiality, according, to the results of the pilot study the (sixty) 60 questionnaires was administered to (sixty) 60 enrollees from three departments within two faculties. Who have studied English as compulsory subject in their first year of four year undergraduate degree program at Quaid-e-Awam University of Engineering Science and technology (QUEST) Nawabshah, Sindh Pakistan, Only (fifty) 50 students returned the complete questionnaires. After the data collection, all the data was entered in statistical package for social sciences (SPSS version 20).

Pilot Study Results and Discussion: The instrument which is proposed for pilot study is a questioner, which is in line with attitude motivation test battery (AMTB) by (Gardner, 1985).In this section of paper, researchers discuss about the initial findings and results based on gender of respondents, Mother tough of respondents, Origin of respondents, Department of respondents, Institutional status of respondents. A complete visual illustration of demographic information based on gender, mother tongue, origin, departments and institutional status is graphically presented respectively for clear understanding and comprehension of piloting results.

\section{Results}

Results based on Gender: The results of the piloting study suggested that in pilot study, the questionnaire asks the first question related to gender of the respondents, out of (fifty) 50 respondents, 06 were female and (forty four) 44 were male. So the result of first question provides confirmation that 
the percentage of male respondents was $88 \%$ higher than that of female respondent which is only $12 \%$. Figure 1 shows the figurative Illustration of gender in terms of percentage

\section{Figure 1: Visual Illustration of gender in terms of percentage}

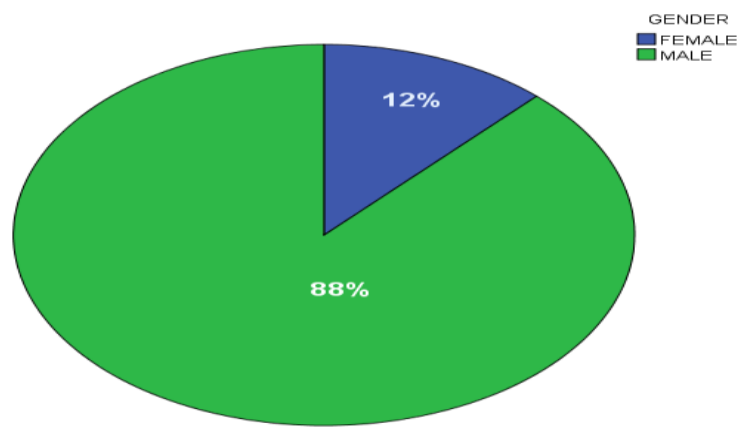

Results based on Mother Tongue: In response to the second question of first part of the questionnaire based on mother tongue of the respondents, The data revealed quite interesting results out of (fifty) 50 , (twenty five) 25 were Sindhi which is 50\% percentage of total investigated population, followed by Urdu that is (ten) 10 in number and is $20 \%$ of the total respondents. And according to the results (five) 5 students were identified as Punjabi which is $10 \%$ of total population and (five) 5 participants were declared as Balochi which is the $10 \%$ just equal to the percentage of Punjabi. More over only (two) 2 respondents were Pashto that is the $4 \%$ of total number of informants. Finally, only (three) 3 students were recognized as Seriki which is the $6 \%$ out of $100 \%$ of total sample the Figure 2 shows the graphical illustration of percentage based on mother tongue ;

\section{Figure 2: visual representation of Mother tongue in terms of percentage}

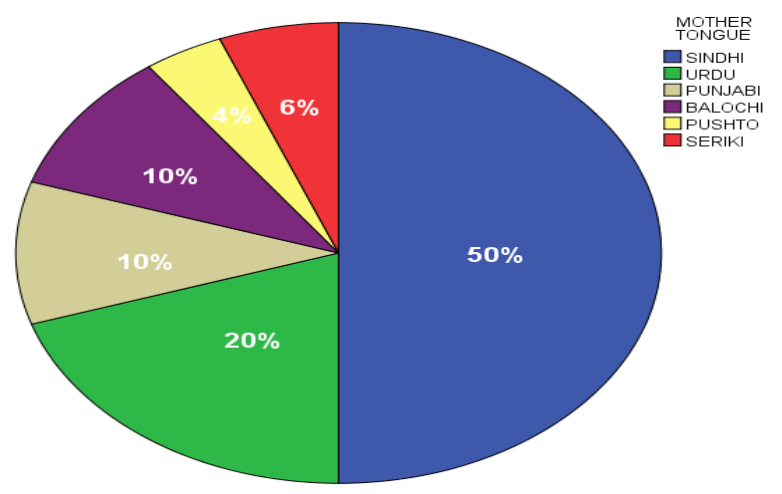

Results based on origion: With regards to results of present study earned on the basis of origin of the respondents. (Forty) 40 informants were belong to rural origin out of (fifty) 50,which majorly form $80 \%$ of the total number of subjects followed by urban which is only (ten) 10 in number out of (fifty) 50 which is $10 \%$ of the total students investigated for pilot study as explained in Figure 3 for more comprehension.

Figure 3: visual illustration of origin of respondents in terms of percentage

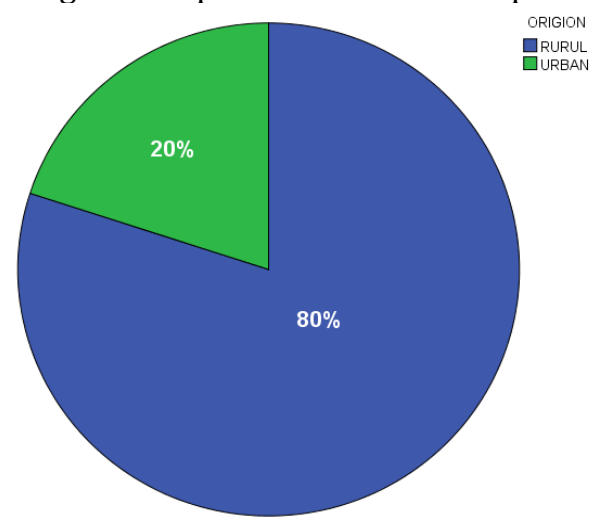


Results based on Departments: For the pilot study, participants were selected from three departments who studied English as compulosry subject in their first year of four years undergraduate degree program. According to results repoted by pilot study out of (fifty) 50 respondents, (sixteen) 16 were belong to Mathematics Department, which is 32\%of total respondents. Number ( seventeen) 17 were from Electrical Engineering department this is 34\% of sample and number (seventeen) 17 students were belong to Mechanical Enginnering Depaerment this is 34\% of total number of students investigated. A comprehensive description of all three departments in terms of percentage is displayed in Figure 4 for detailed understanding.

\section{Figure 4: Graphic Illustration of Departments in terms of percentage}

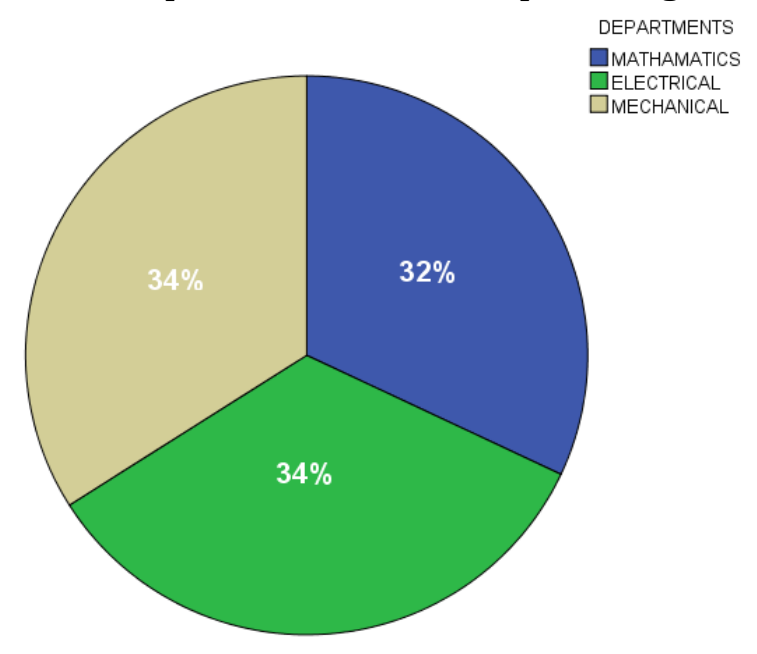

Results based on institutional status: It is interesting to note that results revealed by pilot study on the basis of institutional status are quite surprising. Out of (fifty) 50 subjects, (forty) 40 respondents were identified to belong to the public sector who came from state run schools that is $84 \%$ of investigated students and only (eight) 8 students out of (fifty) 50 were recognized who came from private schooling system that is the only $16 \%$ of the subjects surveyed. As shown in Figure 5.

Figure 5: A figurative Illustration of institutional status in terms of percentage

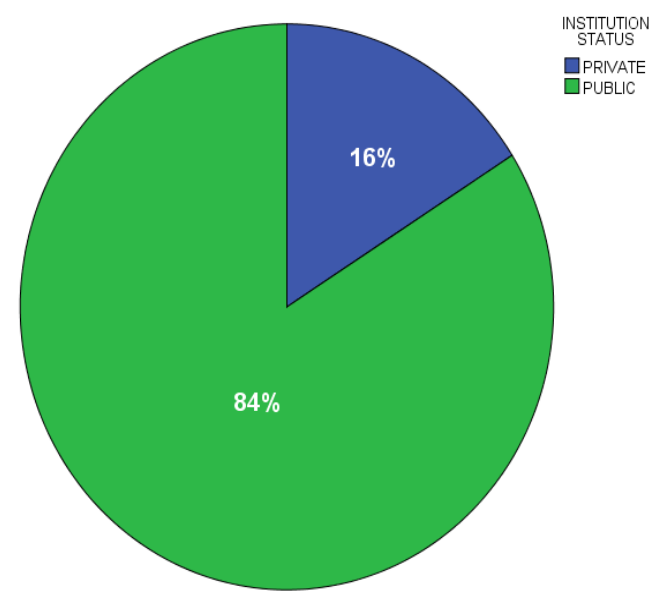

Truly speaking, the present study has earned very informative, interesting and explorative findings on the basis of demographic information in terms of gender, mother tongue, origin, departments and institutional statues which could provide further way for the main study. For detailed information refer the Table 2. 


\begin{tabular}{|c|c|c|}
\hline Target site & $\begin{array}{l}\text { Quaid-E An } \\
\text { technology }\end{array}$ & $\begin{array}{l}\text { m univ } \\
\text { QUEST) }\end{array}$ \\
\hline Year and month of study & First year, $\mathrm{A}$ & ril 2014 \\
\hline Number of departments & Three & (3) \\
\hline Number of questionnaires administered & Sixty & $(60)$ \\
\hline Number of questionnaires returned & Fifty & (50) \\
\hline Female & Six & (6) \\
\hline Male & Forty four & $(44)$ \\
\hline Total & Fifty & $(50)$ \\
\hline Mother tongue & & \\
\hline Sindhi & Twenty five & $(25)$ \\
\hline Urdu & Ten & (10) \\
\hline Panjabi & Five & (5) \\
\hline Balochi & Five & (5) \\
\hline Pashto & Two & (2) \\
\hline Seriki & Three & (3) \\
\hline Origin & & \\
\hline Rural & Forty & $(40)$ \\
\hline Urban & Ten & (10) \\
\hline Institution status & & \\
\hline Private & Eight & (8) \\
\hline Public & Forty two & $(42)$ \\
\hline
\end{tabular}

Validity and Reliability: In this section of study the reliability of instrument, its validity and results of pilot study are discussed at length. Pilot survey is an early experiment conducted before it is ready to use for full study. Purpose of this survey is to measure the validity and reliability of instrument .In order to test research questioner reliability and validity. The level of Cronbach's Alpha is adopted from Gliem \& Gliem (2003).

Table 3: Level of reliability

\begin{tabular}{ll}
\hline Alpha-Cronbach Score & Level of Reliability \\
\hline $1.0>0.9$ & Excelent \\
$0.89>0.8$ & Good \\
$0.79>0.7$ & Accepted \\
$0.69>0.6$ & Questionned \\
$0.59>0.5$ & Lowly accepted \\
$<0.5$ & Not accepeted
\end{tabular}

The reliability coefficient of current study instrument remained as 0.920 , which is very encouraging and a quite high rate of reliability to make sound judgment (Gilem and Gilem, 2003). As displayed in table 4

During the pilot study analysis, for the reliability purpose, the aim of researcher is to standardize the questionnaire, so that the every respondent gets the exact and same order. As brown 2001, suggested that questions should be ordered from shortest and easiest to answer to longest and most difficult to answer. The strength of reliability showed that researchers have spent much time and hours researching and modifying questionnaire only to make the questionnaire true representative on behalf of the researchers. 
Table 4: Cronbach's Alpha reliability Statistics of pilot study on per factor

\begin{tabular}{llll}
\hline S/N & \multicolumn{1}{c}{ Factors } & No Of Items & Cronbach's Alpha \\
\hline 1 & Instrumental Orientation & 04 & 0.919 \\
2 & Integrative Orientation & 03 & 0.919 \\
3 & English Teacher Evaluation & 10 & 0.9195 \\
4 & English Course Evaluation & 09 & 0.9198 \\
& & & \\
5 & English Use Anxiety & 10 & 0.92 \\
6 & Parental Encouragement & 08 & 0.9186 \\
7 & Attitude Towards Learning English & 08 & 0.921 \\
8 & Attitude Towards English Speaking & 08 & 0.9185 \\
9 & People & 07 & 0.9205 \\
10 & Desire To Learn English & 10 & 0.9196 \\
11 & Motivational Intensity & 10 & 0.9201 \\
12 & Interest In Foreign Languages & 09 & 0.9194 \\
& English lass Anxiety & 96 & 0.920 \\
\hline
\end{tabular}

\section{Conclusion}

Ideally speaking, the questionnaire piloting on respondents that are members of the target population then to analyze the results elicited from piloting seem to describe, which items work well and which are problematic, then the developer may have option to delete or revise certain items. It is notified that few subjects have left small number of items unmarked in part two of the questionnaire during pretest survey, which may need to be revised or reworded minutely for more clear understanding before using the instrument for full study. Moreover, such unmarked items generate chances for researcher to include those items in interview questionnaire and in class observation to further probe in the study in order to illicit more information about respondents. One another issue which keenly observed from piloting study is about the misunderstanding of the second question of the third part of survey questionnaire which states "The role of leaders around you can be the great source of encouragement for you to learn English" here most respondents misinterpreted the question instead of understanding it as student leaders the respondents understood as national political leaders like members of senate and national assembly, which need to be rephrased and reworded before using the questionnaire for full study. It is highly recommended from the results obtained from the pilot study that instrument used in this study is valid and reliable and can be confidently used for full study. Finally, it is learnt from the piloted study that the questionnaire is workable and effective due to its excellent level of validity, reliability and suitability according to Gliem \& Gliem (2003).

\section{References}

Dörnyei, Z. (1994). Motivation and motivating in the foreign language classroom. The modern language journal, 78(3), 273-284

Dörnyei, Z. (2000). Motivation in action: Towards a process-oriented conceptualization of student motivation. British Journal of Educational Psychology, 70(4), 519-538.

Gardner, R. C. (1985). Social psychology and second language learning: The role of attitudes and motivation. London: Edward Arnold. 
Gliem, J. A. \& Gliem, R. R. (2003). Calculating, interpreting, and reporting Cronbach's alpha reliability coefficient for Likert-type scales. Midwest Research-to-Practice Conference in Adult, Continuing, and Community Education.

Kobayashi, J. \& Viswat, L. (2007). Cultural differences in motivation to learn. Internet TESL Journal, 8(11).

Oxford, R. \& Shearin, J. (1994). Language learning motivation: Expanding the theoretical framework. The modern language journal, 78(1), 12-28.

Reams, P. \& Twale, D. (2008). The promise of mixed methods: Discovering conflicting realities in the data. International Journal of Research \& Method in Education, 31(2), 133-142. 